Since as many as eight to twelve bands can be detected by the various methods on a single electropherogram, a complete resolution of all the constituents may be feasible by carrying out a continuous electrophoresis with one of the two electrolytes followed by electrophoresis and/or paper chromatography of the fractions obtained.

Istituto Superiore di Sanità,

G. B. Marrni-Bettólo

M. LEDERER

Rome,

and

Institut du Radium, Paris.

March 26.

${ }^{1}$ Klebrle, J., Schmid, H., Waser, P., and Karrer, P., Helv. Chim. Acta, 36, 345 (1953).

${ }^{2}$ Adank, K., Bovet, D., Ducke, A., and Marini-Bettólo, G. B., Gazz. Chim Ital., 83, 060 (1953).

${ }^{3}$ Lederer, M., Anal. Chim. Acta, 6, 267 (1952).

${ }^{4}$ Deckers, W., and Schreiber, J., Naturwiss., 40, 553 (1953).

${ }^{5}$ Burma, D. P., Naturwiss., 41, 19 (1954).

- Marini-Bettólo, G. B., and Miranda, M., Rend. Ist. Sup. Sanità (in the press).

'Lederer, M., and Ward, F. L., Anal. Chim. Acta, 6, 355 (1952).

${ }^{8}$ Durrum, E. L., J. Amer. Chem. Soc., "72, 2943 (1950).

${ }^{\circ}$ Schmid, H., and Karrer, P., Helv. Chim. Acta, 33, 512 (1952).

10 Wieland, Th., Ber., 85, 731 (1952).

\section{A New Spray Reagent for Paper Chromato- graphy of Polyols and Cetoses}

VARIOUS reagents for indicating polyols in paper chromatography have been proposed by Hough, Buchanan et al. and Hockenhull ${ }^{1}$. These reagents all have the disadvantage of reacting also with the sugars, not distinguishing them from the polyols.

We have found a reagent which cnables us to distinguish the polyols from the cetoses but does not reveal the aldoses. Just before use, one volume of 1 per cent vanillin solution in ethanol is mixed with one volume of 3 per cent perchloric acid in water. This is sprayed on the previously dried chromatogram, which is put in an oven at $85^{\circ} \mathrm{C}$. for 3-4 min. Glycerol, erythritol, xylitol, arabitol, adonitol, man. nitol and sorbitol give, on a pale sandy background, spots going from pale blue to lilac pink, then all swiftly turning to pale grey-bluo. Inositol, dihydroxyacetone, the aldopentoses and the aldohexoses do not react, except rhamnose, which gives a brick red spot. Sorbose and fructose give a very deep grey-green spot, easily distinguished from that of the polyols.

The limiting amounts of these substances which can be identified are : $0.005 \mathrm{mgm}$. for the cetohexoses, $0.015 \mathrm{mgm}$. for the hexitols, $0.020 \mathrm{mgm}$. for rhamnose and the pentitols, $0.025 \mathrm{mgm}$. for erythritol and $0.03 \mathrm{mgm}$. for glycerol.

The phenols and some indolic compounds react also with this reagent, which explains why it cannot be employed when using phenol or cresol as chromatography solvent. Similarly, it cannot be used for some acids, especially malonic and gluconic acids, which give the same tint as the polyols. Acid and basic substances must be removed by suitable ionic resins before polyols can be identified by this reagent.

PAUL Godin

(Chargé de Recherches du F.N.R.S.)

Institut Agronomique,

Université de Louvain.

March 28.

1 Buchanan, J. G., Dekker, C. A., and Long, A. G., J. Chem. Soc., 3162 (1950). Hockenhul, D. J.D., Nature, 171,982 (1953). Hough, L., Nature, 165, $400(1950)$.

\section{Odour and Molecular Vibrations}

Dyson's ${ }^{1}$ hypothesis correlating odour specificity with molecular vibration has recently been extended by Wright ${ }^{2}$ to frequencies below about $700 \mathrm{~cm}^{-1}$. In this region he claims to have found a statistically significant correlaticn for sixteen compounds with an almond-like odour, all but one (nitrothiophene) being benzene derivatives.

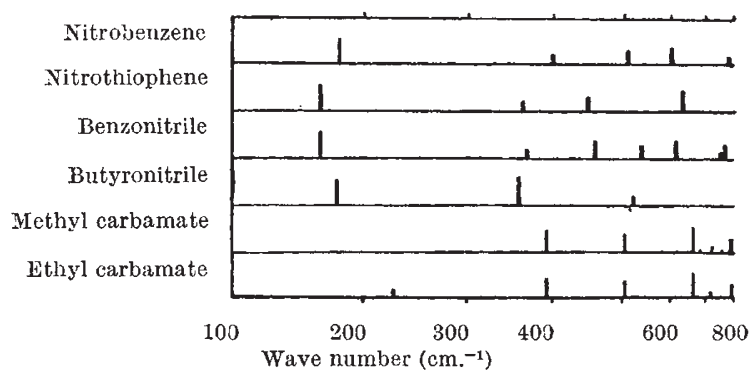

Our racent infra-red studies have included the aliphatic urethanes, the first member of which, methyl carbamate, possesses a distinct almond odour. Its Raman ${ }^{3}$ and infra-red frequencies are shown above together with those of ethyl carbamate and the four spectra depicted by Wright. The spectrum of methyl carbamate bears a closer similarity to the spectra of the 'almond-like group' than the spectrum of butyronitrile does, in spite of the fact that the seemingly characteristic frequency at $170 \mathrm{~cm}^{-1}$ is absent. Due to the lack of a suitable prism, we were unable to extend our investigations to this region; it also appears that the Raman studies were not extended as low as this, so that it is quite possible that methyl carbamate possesses this vibration and a search for such a frequency would be worth while.

On the other hand, the spectrum of ethyl carbamate also shows a similar resemblance to the 'almond-like group' yet has no trace of such an odour, being in fact almost odourless.

These observations emphasize the necessity for a much more detailed survey, covering several groups of compounds of different odour, as suggested by Dyson*. Due to the sparse data in the region below $700 \mathrm{~cm} .^{-1}$ it would seem that some long time must elapse before such a comprehensive survey can be attempted and a reasonable foundation for a molecular vibration theory of odour obtained.

This work was carried out at the Edward Davies Chemical Laboratories, University College, Aberystwyth, by kind permission of Prof. C. W. Davies.

University College of Khartoum, H. E. HaLlaM Khartoum. May 4.

${ }^{1}$ Dyson, G. M., Perf. Essent. Oil Rocord, 19, 456 (1928); 28, 13 (1937); Chem and Indust., 16, 647 (1938).

2 Wright, R. H., Nature, 173, 831 (1954).

${ }^{3}$ Köhlrausch, K. W. F., and Pongratz, A., Z. phys. Chem., B 27, 176 (1934). Wagner, J., Z phys. Chem., B 43, 333 (1939).

4 Dyson, G. M., Nature, 173, 831 (1954).

\section{Indirect Effect of Ultra-Violet Light on Skin Blood Vessels}

$I_{T}$ is known that the ultra-violet wave-lengths responsible for producing vasodilatation or erythema penetrate only a short way into human skin $^{1,2}$. These studies, however, do not by themselves exclude a direct action of ultra-violet light on the blood vessels 